\title{
Prevalence of Vitamin D Deficiency in Exclusively Breast Fed Infants in Suburban Area Lucknow, Uttar Pradesh
}

\author{
Rohit Kumar Agrawal1 ${ }^{1}$, Preeti Sharma², Pradeep Kumar³, Mehek Jaggi', Rachna Sharma ${ }^{5}$ \\ ${ }^{1}$ Department of Pediatrics, T. S. Misra Medical College \& Hospital, Amausi Lucknow, Uttar Pradesh, \\ India. ${ }^{2,3}$ Department of Biochemistry, Santosh Medical College \& Hospital, Ghaziabad, Uttar Pradesh, \\ India. ${ }^{4}$ T. S. Misra Medical College \& Hospital, Amausi Lucknow, Uttar Pradesh, India. ${ }^{5}$ Department of \\ Biochemistry, T. S. Misra Medical College \& Hospital, Amausi Lucknow, Uttar Pradesh, India.
}

\section{ABSTRACT}

\section{BACKGROUND}

Exclusive breastfeeding is recommended up to 6 months of age with all its beneficial effects on child survival. Several studies have shown that adequate intake of vitamin D cannot be met with human milk as the sole source of vitamin D, although risk factors for developing vitamin D deficiency may be low maternal levels of vitamin D, indoor confinement during the day, living at higher altitudes, living in urban areas with tall buildings, air pollution, darker skin pigmentation, use of sunscreen and covering much over the body when outside. An infant who is entirely on breastfeeding and has minimal to no exposure to sunlight is more prone to the development of hypovitaminosis-D. The main purpose of the study was to identify the prevalence \& high-risk groups of hypovitaminosis D in exclusively breastfed babies.

\section{METHODS}

It was a cross-sectional observational study consisting of 30 entirely breastfed healthy full-term babies with a birth weight $>2.5 \mathrm{~kg}$. Babies born to mothers with a history of pre-eclampsia, gestational diabetes, antepartum haemorrhage, tuberculosis, and other chronic medical illnesses were excluded from the study. The period of study was from 1st August 2019 to 30th September 2019. Their serum vitamin D3, serum calcium, serum phosphate, and alkaline phosphatase levels were measured using appropriate methods.

\section{RESULTS}

In our study, 25 infants out of 30 came out as vitamin D deficient. The prevalence of vitamin D3 was found to be $83 \%$.

\section{CONCLUSIONS}

Breastfeeding is of utmost importance but the nutritional status of the mother, proper exposure to the sun, and vitamin D supplementation are the factors that should be taken care of for the prevention of hypovitaminosis D.

\section{KEY WORDS}

Vitamin D3, Hypovitaminosis D, Exclusive Breast Feeding, term babies, infants, Sun Exposure, Rickets
Corresponding Author: Dr. Rachna Sharma, Assistant Professor, Department of Biochemistry, TS Misra Medical College \& Hospital, Amausi Lucknow - 226008, Uttar Pradesh, India. E-mail: drrachna99@gmail.com

DOI: $10.14260 / j e m d s / 2021 / 755$

How to Cite This Article:

Agrawal RK, Sharma P, Kumar P, et al. Prevalence of vitamin $D$ deficiency in exclusively breast fed infants in suburban area Lucknow, Uttar Pradesh. J Evolution Med Dent Sci 2021;10(44):3730-3735, DOI: 10.14260/jemds/2021/755

Submission 28-06-2021,

Peer Review 26-08-2021,

Acceptance 31-08-2021,

Published 11-30-2021.

Copyright (C) 2021 Rohit Kumar Agrawal et al. This is an open access article distributed under Creative Commons Attribution License [Attribution 4.0 International (CC BY 4.0)] 


\section{BACKGROUND}

In today's time role of vitamin D in health and disease is of great concern. There's a huge amount of literature available justifying the link between hypovitaminosis D and a number of other chronic diseases. Keeping a check on the level of vitamin D and calcium during childhood may prevent the probabilities of osteoporosis in the later part of life and also decrease the risks of other chronic diseases which are linked to vitamin D deficiency. Despite many policies developed by the governments of various developed and developing countries, vitamin D supplementation among various risk groups remains a serious health challenge and inadequate to make sure proper sufficiency of vitamin D in several groups of society, especially women and youngsters who are most vulnerable. Breastfeeding is of utmost importance until the age of 6 months thanks to its wide selection of advantages on child survival. Consistent with WHO, exclusive or entirely breastfeeding means the infant is given only breast milk, no other liquids or solids including water are supplemented. ${ }^{1}$

The sole exceptions are oral rehydration solution, drops / syrups of vitamins, minerals, or medicines depending upon the health status of the baby. The American Academy of Paediatrics recommends exclusive breastfeeding up to six months. ${ }^{2}$ The rise of the belief that breast milk is best because it contains ideal and sufficient nutrition making it the right baby food and hence not requiring any additional supplementation has led to 25 hydroxycholecalciferol deficiency in infants. ${ }^{3}$ Vitamin D is the essential precursor of 1, 25 hydroxy-vitamin $\mathrm{D}$, the steroid hormone required for calcium absorption, bone development, and growth in children. During the primary 6 - 8 wks of life, the vitamin D status of infants is decided by the vitamin D levels at birth, which depend upon the vitamin D status of the mother. 4

It can readily cross the placenta and offer a point of protection for a couple of months against vitamin D deficiency within the case of infants born to mothers having adequate vitamin D levels. Serum half-life time of 25 hydroxycholecalciferol, abbreviated as $25(\mathrm{OH})$ D3 is approximately 3 weeks. Breast milk concentration of vitamin $\mathrm{D}$ is low $(<20 \mathrm{IU} / \mathrm{l})$ and is inadequate for the needs of the growing infant. 5

Vitamin D in breast milk relates to mothers' vitamin D intake, skin pigmentation, and sunlight exposure. Humans obtain their vitamin D requirement from sunlight. ${ }^{6}$ An infant who is entirely breastfed with minimal to no exposure to sunlight is at a greater risk of developing a vitamin-D deficiency. ${ }^{7}$

The classical function of vitamin D is to regulate calcium absorption in the body and maintain a healthy skeleton. Beyond this, there are many extraskeletal functions of vitamin D as well. The non-classical functions of vitamin D involve regulation of cellular proliferation, differentiation, apoptosis, and innate and acquired immunity. ${ }^{8}$

Many scientific pieces of evidence linking vitamin D to various chronic diseases in children and adults are emerging. Rickets is an example of extreme vitamin D deficiency, with a peak incidence between 3 and 18 months of age. A state of deficiency that occurs months before rickets is obvious on physical examination, and the deficiency state may also present with hypocalcemic seizures, ${ }^{9}$ growth failure, lethargy, irritability, and a predisposition to respiratory infections during infancy. ${ }^{10}$ Two types of presentation of vitamin D deficiency have been described in children.11 The first is symptomatic hypocalcaemia (including seizures) occurring during periods of rapid growth, with increased metabolic demands, long before any physical findings or radiologic evidence of vitamin D deficiency occurred. The second clinical presentation is that of more chronic disease, with rickets and / or decreased bone mineralization and either normocalcemia or asymptomatic hypocalcaemia. Prevention of vitamin D deficiency and achieving adequate intake of vitamin D and calcium throughout the childhood may reduce the risk of osteoporosis as well as other long-latency disease processes that have been associated with vitamin Ddeficiency states in adults. ${ }^{12-15}$

Rickets attributable to vitamin D deficiency is known to be a condition that is preventable with an adequate nutritional intake of vitamin D. ${ }^{16}$ A prospective observational study by Soumya M. has shown that adequate need of vitamin D cannot be met with human milk being the sole source of vitamin D. The mean vitamin D level in infants was 25.72 $\mathrm{ng} / \mathrm{ml}( \pm 11.31 \mathrm{ng} / \mathrm{ml})$ and in the mothers' it was 22.09 $\mathrm{ng} / \mathrm{ml}( \pm 9.17 \mathrm{ng} / \mathrm{ml}) \cdot{ }^{17}$

In their study, Jain et al. had reported that $66.7 \%$ of infants and $81.1 \%$ of mothers were found to be vitamin D deficient, and $19.8 \%$ of infants and $11.6 \%$ of mothers had vitamin D insufficiency. This study was conducted at AIIMS New Delhi. ${ }^{18}$ Jagzape $\mathrm{T}$ et al. in their study reported that 93.3 $\%$ of the babies had vitamin D deficiency and the mean vitamin D level was $8.871 \pm 4.78 \mathrm{ng} / \mathrm{ml}$. These results were very high when compared to the present study. ${ }^{19}$

During the past decades, there were very few cases of hypovitaminosis $\mathrm{D}$ in infants due to the practice of providing adequate sunlight exposure to the baby. Nowadays with increased urbanization, this practice has been declined. The main objective of the study was to identify the prevalence \& high-risk groups of hypovitaminosis $\mathrm{D}$ in exclusively breastfed babies so that early interventions can be taken to prevent the severe clinical manifestations of vitamin D deficiency diseases.

\section{METHODS}

It was a cross-sectional observational study consisting of 30 exclusively breastfed healthy term babies with birth weight > $2.5 \mathrm{~kg}$. Due to the short period (2 months) for conducting research, this study was small-sized consisting of only 30 subjects according to the rule of thumb. ${ }^{20}$ Babies born to mothers with a history of pre-eclampsia, gestational diabetes, antepartum haemorrhage, tuberculosis and other chronic medical illnesses were excluded from the study. The period of study was from $1^{\text {st }}$ August 2019 to 30 3 th $^{\text {September }} 2019$ in T. S Misra Medical College and Hospital, Lucknow. This article has used data of human participants for which permission from the Institutional Ethics Committee was taken before carrying out the study. Serum levels of vitamin D 25 (OH) D3 and calcium, phosphate, and alkaline phosphatase have been estimated by kit based methods with standard procedures.

- Vitamin D3 has been assayed by enzyme-linked fluorescent assay (ELFA) method by VIDAS $25 \mathrm{OH}$ Vitamin D Total kit from Biomerieux Vidas

Assay range: $20-100 \mathrm{ng} / \mathrm{ml}$. 
Serum Hypovitaminosis D has been defined as $<20 \mathrm{ng} /$ $\mathrm{ml}$ of $25-(\mathrm{OH})$ vitamin $\mathrm{D}$ in the blood.21

\begin{tabular}{|cc|}
\hline Status & $25-(\mathrm{OH})$ Vitamin D in $\mathrm{ng} / \mathrm{ml}$ \\
Deficient & $<20$ \\
Insufficient & $20-29$ \\
Sufficient & $30-100$ \\
Potential toxicity & $>100$ \\
\hline
\end{tabular}

- Serum Calcium by Arsenazo III method by Avantor Benesphera Calcium Arsenazo III liquid stable kit.

Assay Range: 8 - $11 \mathrm{mg} / \mathrm{dl}$.

- Serum Phosphorous by modified Gomori's method spectrophotometrically by Tulip Diagnostic Phosphorus Kit.

Assay Range: $4.0-6.5 \mathrm{mg} / \mathrm{dl}$

- Serum Alkaline Phosphatase by DGKC method by Avantor Alkaline Phosphatase DGKC liquid stable kit.

Assay Range: 270 - 810 IU / L

Obstetric history of the mothers was taken and haemoglobin levels of mothers were estimated.

\section{Statistical Analysis}

SPSS version V26 was used. Chi-square statistics and Pearson's coefficient were applied to the data.

\section{RESULTS}
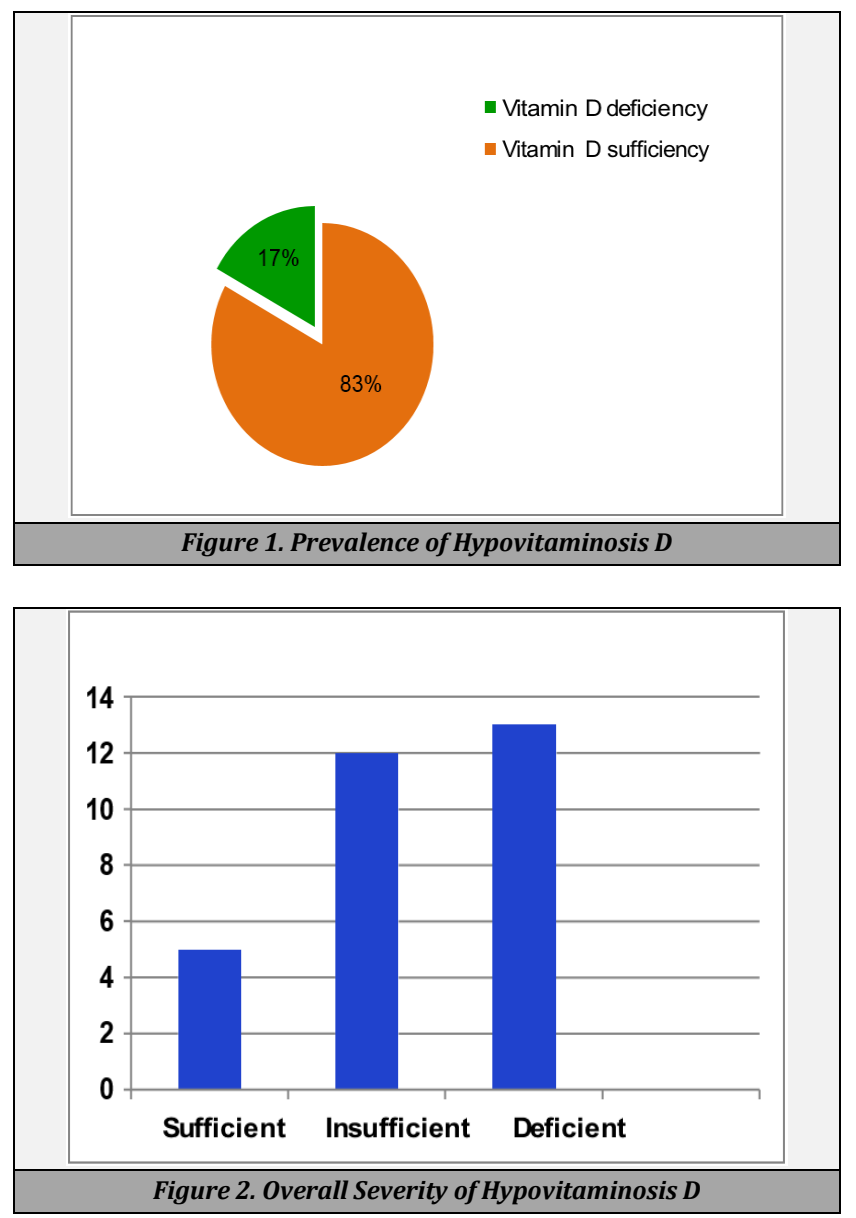

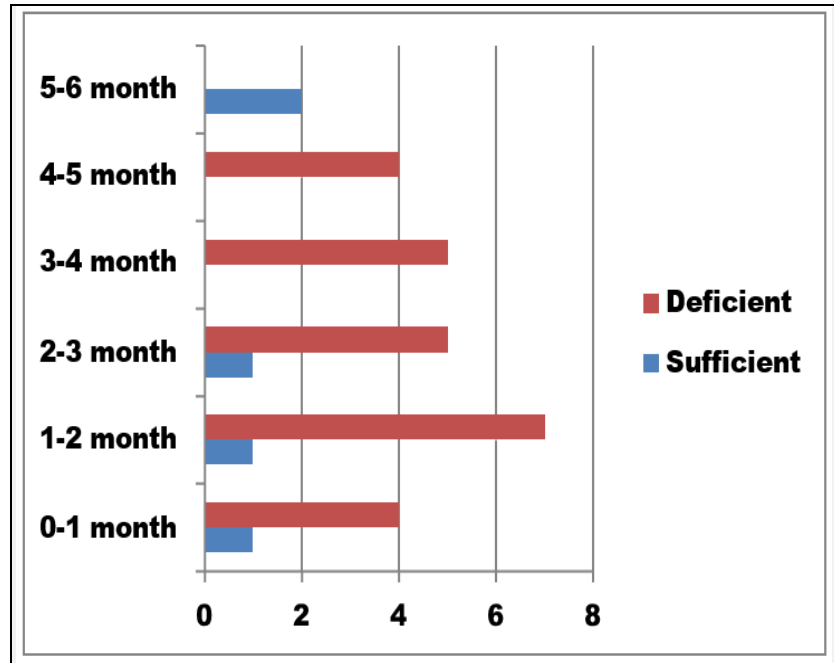

Figure 3. Age Distribution of Hypovitaminosis D

Chi-square statistic is 11.94 . The $p$-value is 0.035 and the result is significant.

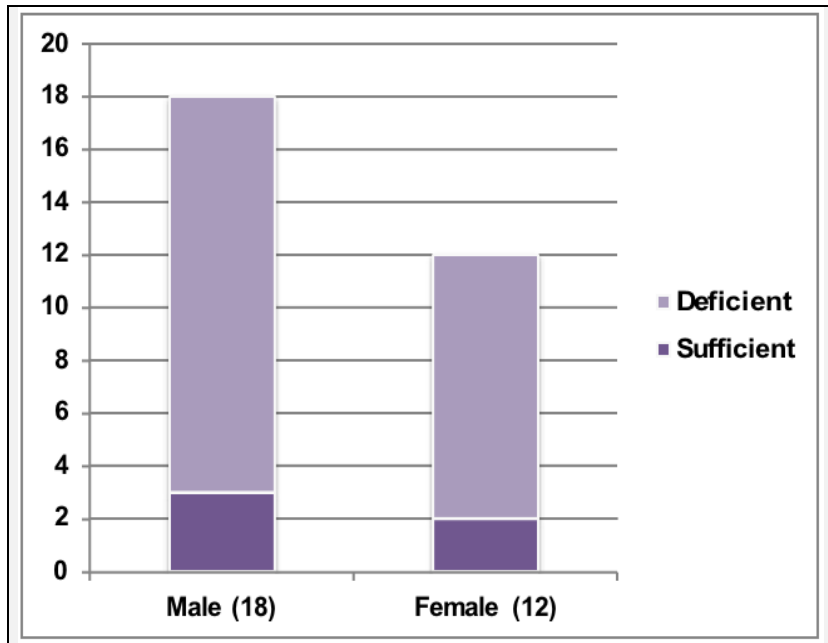

Figure 4. Gender Related Vitamin D Deficiency

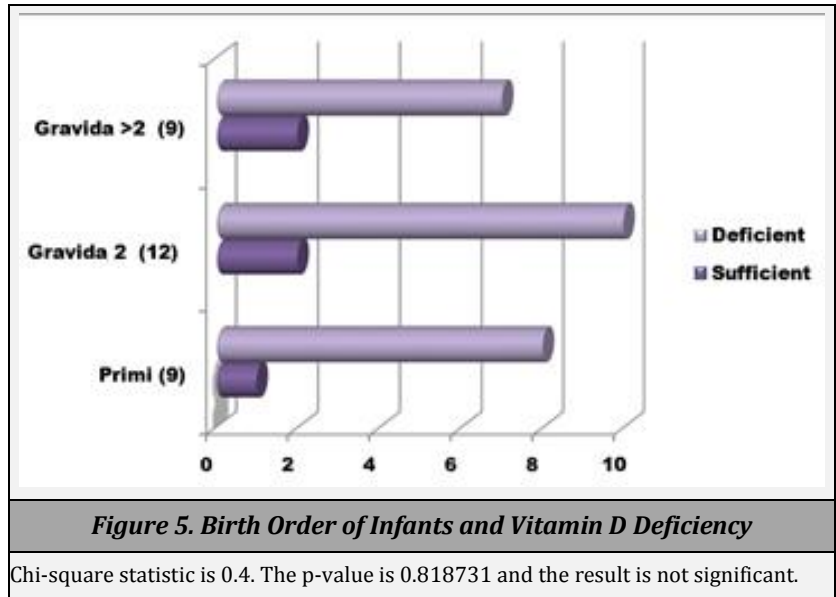

In my study, 25 infants out of 30 came out to be vitamin D deficient. The prevalence of vitamin D3 was $83 \%$ (Figure 1). In my study, 16 infants were found to be slightly hypocalcaemic. The remaining 14 were normocalcaemic. Phosphate levels were normal in all infants. Alkaline phosphatase was found to be raised in all infants. 


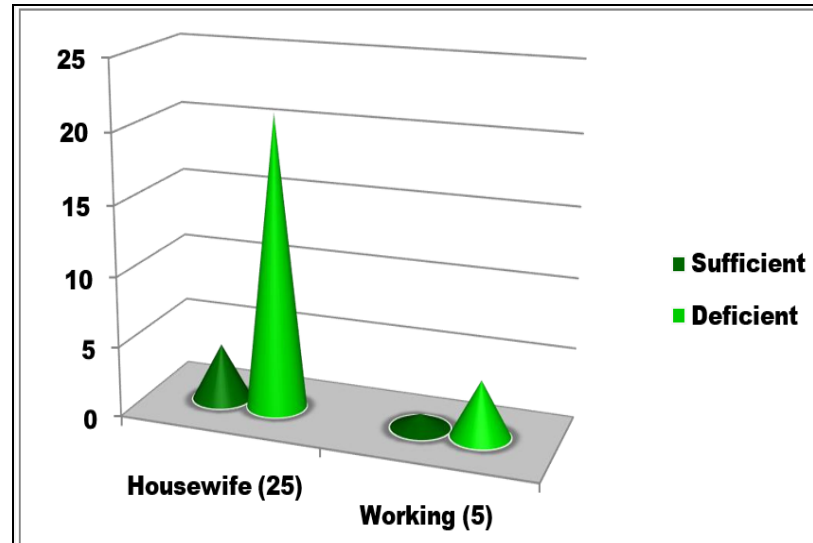

Figure 6. Occupation of Mother and Vitamin D Deficiency in Infants Chi-square statistic is 0.048 . The p-value is 0.826 and the result is not significant

\section{DISCUSSION}

30 exclusively breastfed healthy term babies with birth weight $>2.5 \mathrm{~kg}$ were taken as study population and serum levels of vitamin D 25-(OH) D3 and calcium, phosphate, and alkaline phosphatase have been estimated using standard procedures. In our observation, we found that $83 \%$ of the babies who were entirely breastfed were vitamin $\mathrm{D}$ deficient. Other factors like nutritional status, occupation of mother and order of birth as well, sex of the baby, etc. also has a task to play within the same.

We found a high prevalence of vitamin D deficiency within the term, appropriate for gestational age breastfed infants and their mothers. This is much higher than the prevalence reported in studies from the United States ${ }^{22,23}$ but consistent with the findings of studies from other countries like Greece, UAE, and Pakistan ${ }^{24-26}$ and with previous Indian studies. $27-30$

In this study, the prevalence of vitamin D3 deficiency was $83 \%$. A similar report by Adekunle Dawodu et al. shows an $82 \%$ prevalence of hypovitaminosis D out of 72 infants. ${ }^{31}$ Vitamin D can readily cross the placenta and the levels in neonates are approximately $67 \%$ of the maternal serum concentrations. ${ }^{3}$ Inadequate sunlight and no vitamin D supplementation for more than 30 days increase the probability of developing vitamin D deficiency. In the present study, $80 \%, 87.5 \%, 83 \%, 100 \%$ of infants were found to be vitamin $\mathrm{D}$ deficient between the age group of 0 - 1 month, 1 2 months, 2 - 3 months, and 4 - 5 months respectively. The reason for this high prevalence in India may be related to decreased cutaneous synthesis owing to higher skin pigmentation; and lower duration as well as surface area exposed to the sun due to greater coverage of body and lesser participation in outdoor activities, in particular among females, starting from adolescence. The traditional custom of giving infants an oil massage in the sunlight for 15 - $30 \mathrm{~min}$ before bathing has gradually declined, especially in the cities. The intake of vitamin $\mathrm{D}$ is inadequate as food items (except infant formula) are not fortified and there is no policy of routine vitamin D supplementation in pregnant / lactating women and infants. Indian diet, low in calcium and high in phytates, may also contribute by causing secondary hyperparathyroidism, increased conversion of $25(\mathrm{OH}) \mathrm{D}$ to polar metabolites and inactive 24, 25 dihydroxyvitamin D3.32,33

A male predominance was noticed in this study shown in Fig 4 similar to the study done by You Jin Choi on Vitamin D deficiency in infants aged 1 to 6 months. ${ }^{34}$ In the present study, the physiological relevance of hypovitaminosis D is corroborated by an almost ubiquitously elevated ALP concentration; infants' lower sun exposure maybe because of temperatures reaching up to $45^{\circ} \mathrm{C}$ during summer months. The current recommendation of the American Academy of Paediatrics is that all infants and children, including adolescents, should have a minimum daily intake of $400 \mathrm{IU}$ of vitamin $\mathrm{D}$ beginning soon after birth ${ }^{35}$

More vitamin D consumption is required for frequent multiple pregnancies. ${ }^{3}$ In this study $82 \%$ of infants born to primi mothers, $83 \%$ and $77 \%$ infants born to multi-para mothers were found vitamin $\mathrm{D}$ deficient as shown in fig 5 . Mothers who are housewives are much less exposed to sunlight in comparison to working mothers. This may be because they mostly stay indoors during the daytime. According to Zeghoud et al. $5 \%$ of women exposed to sunshine and $59 \%$ of women who were not exposed to sunshine had low concentrations of 25-(OH)D 3.36 In this study, $84 \%$ of infants born to mothers who were housewives and $80 \%$ of infants whose mothers were working showed deficient vitamin D status. There is a strong relationship between maternal and foetal circulating $25(\mathrm{OH})$ D 3 levels. According to Marilyn Urrutia-Pereira et al. nutrients can modify the immune and metabolic programming during the sensitive foetal and postnatal development period of life. ${ }^{37}$ In this study, Fig 8 shows that $87 \%$ of infants born to anaemic mothers were found to be vitamin D deficient. Zeghoud et al. in their other study has shown that supplementation with 1000 but not $500 \mathrm{IU} /$ day of ergocalciferol for a month could normalize the PTH levels in infants with subclinical vitamin D deficiency. ${ }^{38}$ However, for any given infant, it is difficult to determine reliably the amount of sunlight exposure sufficient to maintain normal vitamin $D$ status, as it is influenced by many factors such as clothing, skin pigmentation, sunscreen use, weather conditions, latitude, air pollution, time of the day and time of the year. ${ }^{39}$

\section{CONCLUSIONS}

In conclusion, the present study found a very high prevalence of vitamin D deficiency in healthy term born infants in all age groups till 6 months. This study shows that $83 \%$ of the babies that were entirely breastfed with no additional supplementation were vitamin $\mathrm{D}$ deficient. This is also affected by the nutritional status of the pregnant mother, order of birth, occupation of the mother, and sex of the infant. However, breastfeeding is of utmost importance until the age of 6 months due to its wide range of benefits for the child's survival but adequate sun exposure can provide a sufficient amount of vitamin D3. Larger studies and meta-analyses should be conducted to confirm the findings of the present study and develop recommendations for vitamin D supplementation for pregnant and lactating women and young infants.

Data sharing statement provided by the authors is available with the full text of this article at jemds.com. 
Financial or other competing interests: None.

Disclosure forms provided by the authors are available with the full text of this article at jemds.com.

All the authors duly acknowledge the support of the management of TSM Medical College \& Hospital, Lucknow, UP, India.

\section{REFERENCES}

[1] World Health Organization. Indicators for assessing infant and young child feeding practices: definitions and measurement methods. Geneva: World Health Organization and the United Nations Children's Fund (UNICEF),

2021.

https://apps.who.int/iris/rest/bitstreams/1341846/ret rieve]

[2] Section on Breastfeeding. Breastfeeding and the use of human milk. Pediatrics 2012;129(3):e827-41.

[3] Balasubramanian S, Ganesh R. Vitamin D deficiency in exclusively breast-fed infants. Indian J Med Res 2008;127(3):250-5.

[4] Holick MF, MacLaughlin JA, Doppelt SH. Regulation of cutaneous previtamin D3 photosynthesis in man: skin pigment is not an essential regulator. Science 1981;211(4482):590-3.

[5] Kamao M, Tsugawa N, Suhara Y, et al. Quantification of fat-soluble vitamins in human breast milk by liquid chromatography-tandem mass spectrometry. J Chromatogr B Analyt Technol Biomed Life Sci 2007;859(2):192-200.

[6] Specker BL. Do North American women need supplemental vitamin D during pregnancy or lactation? Am J Clin Nutr 1994;59(Suppl 2):484S-490S, discussion 490S-491S.

[7] Kreiter SR, Schwartz RP, Kirkman HN Jr, et al. Nutritional rickets in African American breast-fed infants. J Pediatr 2000;137(2):153-7.

[8] Umar M, Sastry KS, Chouchane AI. Role of Vitamin D beyond the skeletal function: a review of the molecular and clinical studies. Int J Mol Sci 2018;19(6):1618.

[9] Hatun S, Ozkan B, Orbak Z, et al. Vitamin D deficiency in early infancy. J Nutr 2005;135(2):279-82.

[10] Najada AS, Habashneh MS, Khader M. The frequency of nutritional rickets among hospitalized infants and its relation to respiratory diseases. J Trop Pediatr 2004;50(6):364-8.

[11] Ladhani S, Srinivasan L, Buchanan C, et al. Presentation of vitamin D deficiency. Arch Dis Child 2004;89(8):7814.

[12] Willer CJ, Dyment DA, Sadovnick AD, et al. Timing of birth and risk of multiple sclerosis: population based study. Br Med J 2005;330(7483):120.

[13] Kamen DL, Cooper GS, Bouali H, et al. Vitamin D deficiency in systemic lupus erythematosus. Autoimmun Rev 2006;5(2):114-7.

[14] Garland CF, Comstock GW, Garland FC, et al. Serum 25(OH)D and colon cancer: eight-year prospective study. Lancet 1989;2:1176-8.

[15] Giovannucci E, Liu Y, Rimm EB, et al. Prospective study of predictors of vitamin D status and cancer incidence and mortality in men. J Natl Cancer Inst 2006;98:451-9.
[16] Thacher TD, Fischer PR, Strand MA, et al. Nutritional rickets around the world: causes and future directions. Ann Trop Paediatr 2006;26(1):1-16.

[17] Soumya M. Study of vitamin D levels in exclusively breastfed term infants in a tertiarycare centre. Int J Contemp Pediatr 2018;5:71-4.

[18] Jain V, Gupta N, Kalavani M, et al. Vitamin D deficiency inhealthy breastfed term infants at 3 months and their mothers in India: seasonal variation and determinants. Indian J Med Res 2011;133(3):267-73.

[19] Jagzape T, Khan S. Vitamin D levels in exclusively breastfed infants less than six months of age: Do they need supplementation? Sri Lanka J Child Health 2014;43(2):92-6.

[20] Martinez-Abrain A. Is the " $n=30$ rule of thumb" of ecological field studies reliable? A call for the greater attention to the variability in our data. Anim Biodiveres Conserv 2014;37(1):95-100.

[21] Holick MF. Vitamin D deficiency. N Engl J Med 2007;357(3):266-81.

[22] Ziegler EE, Hollis BW, Nelson SE, et al. Vitamin D deficiency in breastfed infants in Iowa. Pediatrics 2006;118(2):603-10.

[23] Gordon CM, Feldman HA, Sinclair L, et al. Prevalence of vitamin D deficiency among healthy infants and toddlers. Arch PediatrAdolesc Med 2008;162(6):505-12.

[24] Challa A, Ntourntoufi A, Cholevas V, et al. Breastfeeding and vitamin D status in Greece during the first 6 months of life. Eur J Pediatr 2005;164(12):724-9.

[25] Dawodu A, Agarwal M, Hossain M, et al. Hypovitaminosis $\mathrm{D}$ and vitamin D deficiency in exclusively breast-feeding infants and their mothers in summer: a justification for vitamin D supplementation of breast-feeding infants. J Pediatr 2003;142(2):169-73.

[26] Atiq M, Suria A, Nizami SQ, et al. Vitamin D status of breastfed Pakistani infants. Acta Paediatr 1998;87(7):737-40.

[27] Sachan A, Gupta R, Das V, et al. High prevalence of vitamin $\mathrm{D}$ deficiency among pregnant women and their newborns in northern India. Am J Clin Nutr 2005;81(5):1060-4.

[28] Goswami R, Gupta N, Goswami D, et al. Prevalence and significance of low 25- hydroxyvitamin D concentrations in healthy subjects in Delhi. Am J Clin Nutr 2000;72(2):472-5.

[29] Bhalala U, Desai M, Parekh P, et al. Subclinical hypovitaminosis D among exclusively breastfed young infants. Indian Pediatr 2007;44(12):897-901.

[30] Seth A, Marwaha RK, Singla B, et al. Vitamin D nutritional status of exclusively breast fed infants and their mothers. J Pediatr Endocrinol Metab 2009;22(3):241-6.

[31] Dawodu A, Agarwal M, Hossain M, et al. Hypovitaminosis $\mathrm{D}$ and vitamin $\mathrm{D}$ deficiency in exclusively breast-feeding infants and their mothers in summer: a justification for vitamin D supplementationof breast-feeding infants. The Journal of Pediatrics 2003;142(2):169-73.

[32] Clements MR, Johnson L, Fraser DR. A new mechanism for induced vitamin D deficiency in calcium deprivation. Nature 1987;325(6099):62-5.

[33] Harinarayan CV, Ramalakshmi T, Prasad UV, et al. High prevalence of low dietary calcium, high phytate 
consumption and vitamin D deficiency in healthy south Indians. Am J Clin Nutr 2007;85(4):1062-7.

[34] Choi YJ, Kim MK, Jeong SJ. Vitamin D deficiency in infants aged 1 to 6 months. Korean Journal of Pediatrics 2013;56(5):205-10.

[35] Wagner CL, Greer FR, American Academy of Pediatrics Section on Breastfeeding et al. Prevention of rickets and vitamin D deficiency in infants, children and adolescents. Pediatrics 2008;122(5):1142-52.

[36] Zeghoud F, Thoulon JM, Gillet JY, et al. Effects of sunlight exposure on vitamin D status in pregnant women in France. J Gynecol Obstet Biol Reprod (Paris) 1991;20(5):685-90.
[37] Urrutia-Pereira M, Solé D. Vitamin D deficiency in pregnancy and its impact on the fetus, the newbornandin childhood. Rev Paul Pediatr 2015;33(1):104-13.

[38] Zeghoud F, Vervel C, Guillozo H, et al. Subclinical vitamin $D$ deficiency in neonates: definition and response to vitamin D supplements. Am J Clin Nutr 1997;65(3):7718.

[39] Greer FR. Issues in establishing vitamin D recommendations for infants and children. Am J Clin Nutr 2004;80(Suppl 6):1759S-62S. 